\title{
World's Malnutrition Paradox; Gaps in Looking Back and Looking Ahead
}

\author{
Kutwah Moses Amram
}

Registered Public Health Nutritionist

\author{
*Corresponding author \\ Kutwah Moses Amram, Examinations Department, Kenya Nutritionists and \\ Dieticians Institute, Kenya. E-mail: kutwahmoses@gmail.com
}

Submitted: 02 July 2019; Accepted: 12 Sep 2019; Published: 04 Oct 2019

\begin{abstract}
Objective: This paper examines paradigms in the double burden of malnutrition. It explores the speed of nutrition transition, summarizes the drifts and trends in prevalence rates between under nutrition and overnutrition.
\end{abstract}

Design and Setting: Review of outcomes that focus on large scale surveys, national and global representative studies on diet, physical activity, obesogenic environment and obesity among children, adolescents and adults.

Subjects: The WHO guidelines for classifying and defining overweight and obesity are used for children and adolescents and the body mass index of $\geq 25 \mathrm{~kg} / \mathrm{m}^{2}$ and $30 \mathrm{~kg} / \mathrm{m}^{2}$ are used for adult's overweight and obesity respectively.

Results: The nutrition transition shifts are examined from the $20^{\text {th }}$ century to the current century in Europe. China, USA and the low and middle income countries of Africa, Asia and Middle East. Paradoxically, the two forms of malnutrition exist. Undernutrition is observed to be decreasing whereas overnutrition is increasing rampantly. The problem is cutting across all classes of people; rich or poor and the magnitude is becoming a health burden especially in developing countries. The shifts have dominated to overweight, obesity and diet related comorbidities such as cardiovascular diseases, diabetes and some cancers. Conclusive evidence on the global malnutrition situation is still elusive but available data forecasts trend in the shifts.

Conclusion: This work shows that the two forms of malnutrition exists in discordance but overweight and obesity is encroaching rapidly and is a risk to diet-related NCDs, yet they can be significantly reduced.

Keywords: Under Nutrition, Over Nutrition, Overweight, Obesity, Diet, Physical Activity, Non-Communicable Diseases.

\section{Introduction}

The global community is contending with manifold problems of malnutrition [1]. There is increasing body of evidence that regardless of significant steps the world has taken towards improving nutrition and the related burdens, the scale of malnutrition is still overwhelming [1,2]. Global nutrition statistics reveal that out of 195 countries worldwide, 88 countries faces a serious burden of either 2 or 3 forms of malnutrition [1]. Approximately 15.95 million children are both stunted and wasted; 8.23 million children suffer from both stunting and overweight. Amongst the 141 countries with consistent data on the 3 forms of malnutrition, 88 per cent, 124 countries exhibit the two forms of malnutrition and 29 per cent, 41 countries exhibit the three forms of malnutrition; anemia in women of child-bearing age, overweight and childhood stunting.
Currently, the world faces an epidemiological transition from the high prevalence of infectious diseases allied to under nutrition, food insecurity and poor water, sanitation and hygiene practices to one of high prevalence of overweight, obesity and diet related non-communicable diseases linked to obesogenic environments and lifestyles $[3,4]$. While initially, obesity was thought to be a problem of the high income urban populations, the prevalence rates are increasing rapidly in low and middle income countries [5]. Today, being overweight or obese is a major health catastrophe affecting all generations and classes of people in the society; rich or poor [6]. Obesity rates are too big to ignore [5,7]. It is the most serious public health challenge of the $21^{\text {st }}$ century. In the coming generation, the trends are expected to be worse if thoughtful action is not taken.

Overweight and obesity during childhood can propagate to adulthood and predispose one at risk of developing diet related noncommunicable diseases such as diabetes, cardiovascular diseases and some forms of cancer at a very young age [8]. These delayed 
degenerative diseases are unexpected, preventable and therefore necessitate new ways of thinking about aging, disease morbidity, mortality and certainly how life will be lived in the near future.

This paper summarizes data from various articles, national reports, Demographic Health and Information Surveys (DHIS), Multiple Indicator Cluster Surveys (MICS), data from national household surveys and routine reporting systems. The review focuses on trends in malnutrition levels, especially over-nutrition, reflects the areas attributed to attenuate the prevalence rates and capitalizes on driving factors that need to be arrested.

\section{Global Scope and Trends of the Problem}

The global nutrition report of 2017 reveals that 2 billion adults are overweight or obese, 155 million children under five years of age are stunted, 52 million are wasted and 41 million children are overweight [1]. In 2016 the rates were a little lower, 1.9 billion adults, 18 years and older were overweight, 600 million of these were obese and 462 million adults were underweight [9]. On the other hand, 42 million children under the age of five years were overweight or obese, 156 million were stunted and 50 million were wasted. The report farther reveals that at least 2.8 million people are estimated to die every year as a result of being overweight or obese. And, out of the 129 countries with data, 57 countries face serious levels of under nutrition, overweight and obesity. Under nutrition was associated with about 45 per cent of mortality rates of children under five years of age [10]. Majority of these deaths are reported to occur in low and middle-income countries. Questionably, the trends of childhood overweight and obesity are predominantly increasing at alarming rates in these same countries $[10,11]$.

In 2014, out of 1,929 million adults, 947 million men and 982 million women were overweight. Out of 741 million adults, 266 million men and 375 million women were obese. In the U.S nearly 35 per cent of American is obese. According to the Center for Disease Control and Prevention (CDC),obesity is a national epidemic: it is not just a weight problem; it potentiates importunate health implications to a person's psychological, physical and metabolic health [12]. Latest figures predict that by 2030, 42 per cent of adult population in USwill be obese, 83 per cent of men and 73 per cent of women in Australia will either be obese or overweight by 2025 [13,14].

Popkin demonstrates that the rate of change to obesity in low and middle income countries is predominantly increasing at worrying rates than in high income countries [5]. The rates in these countries, Mexico, Morocco, Seychelles, Egypt, and Thailand are either greater than or equal to that of countries like USA [4,5]. A research led by scientists from Imperial College in London and published in the Lancet suggests there are more overweight and obese people than underweight and undernourished ones [15]. The study pooled data from 186 countries. The findings revealed that the number of obese people globally rose from 105 million in 1975 to 641 million in 2014. Furthermore, the number of underweight people rose to 462 million from 330 million over the same period. Global obesity rates among men went up from 3.2 per cent in 1975 to 10.8 per cent while among women the values raised from 6.4 per cent in 1975 to 14.9 per cent in 2014; this is equivalent to 375 obese women and 266 million obese men globally as at 2014, the study revealed.

Prof Ezzati, the lead, Author said, "our research predicts that the probability of reaching the World Health Organization's global obesity target which aimed for no rise in obesity above 2010 levels by 2025 would be close to zero." In another study documented by Non-communicable Disease Risk Factor Collaboration (NCD-RisC), the mean BMI and prevalence of obesity increased worldwide in children and adolescents from 1975 to 2016 [16]. Despite the rise, more children and adolescents are still moderately underweight than obese. However, if the 2000 trends continue, there is a high possibility that children' and adolescents' obesity rates will surpass average and underweight trends by 2022. Below are graphical representation of global trends of stunting and overweight and obesity.

Number of Children Under-5 Affected By Stunting and Overweight 1990 - 2016

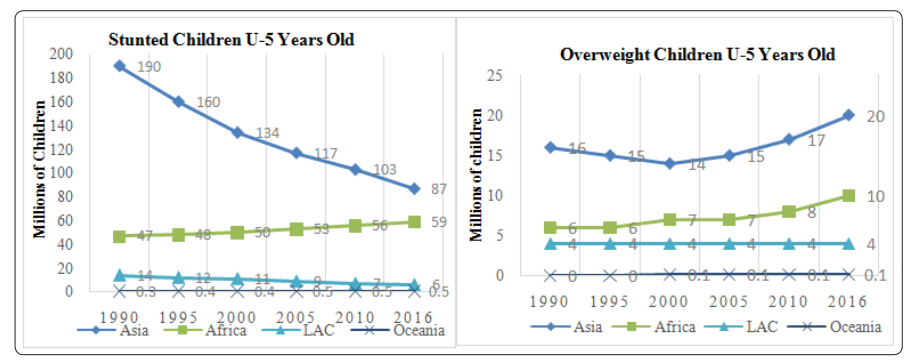

Source: Data adopted from UNICEF/WHO/World Bank Group Joint Child Malnutrition Estimates 2017.

Note: LAC - Latin America and Caribbean

Prevalence of Adults Overweight and Obesity and Adult Obesity (18 years and older), 2010-2014

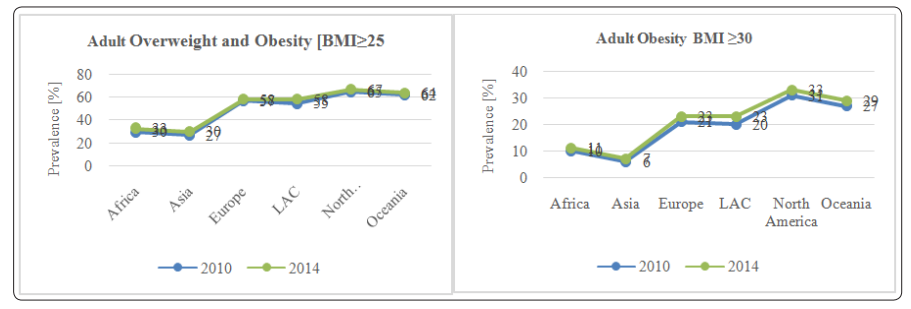

Source: Data adopted from World Health Organization Global Health Observatory data repository and NCD Risk Factor Collaboration. Note: LAC - Latin America and the Caribbean countries. $\mathrm{N}=189$ countries

Progress towards meeting global nutrition targets as at 2017

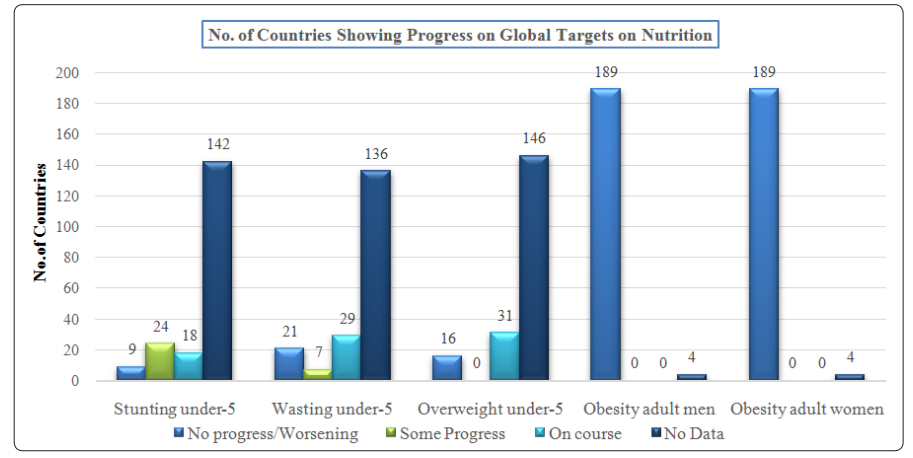

Source: Global Nutrition Report 2017, data adoptedfrom UNICEF/ WHO/World Bank Group Joint Child Malnutrition Estimates 2017, Stevens GA et al, 2013 and NCD Risk Factor Collaboration, 2017. 
Note: $\mathrm{N}=193$ some countries are excluded from analysis because the methodological work need reinforcement

\section{Africa Malnutrition Patterns}

Focusing on Africa, the African Nutrition Report has shown that under-nutrition is still persistent in the region [17]. The number of stunted children has increased and on the other hand, an alarming number of children under five years are now classified as overweight, highlighting an issue of grave inequality in countries of one continent. The report reveals that, whereas the prevalence of stunting reduced from (38.3 per cent) in 2000 to ( 30.3 per cent) in 2016, the absolute number of stunted children are in fact increasing; from 50.4 million in 2000 to 58.5 million in 2016. Nearly, 10 million children in Africa are overweight, and figures attest that overweight children in Africa rose by a margin of greater than 50 per cent from 2000 to 2015 . This becomes ironical owing to the fact that Africa is considered to possess enormous potential for growth due to habitation of huge natural resources and productive youthful populations.

On the other end of the spectrum, the report found that 24 countries have overweight rates of between 3 and 10 per cent and there are countries with prevalence above this range. They include Algeria (12.4 per cent), Botswana (11.2 per cent), Comoros (10.9 per cent), Seychelles (10.2 per cent) and South Africa (10.9 per cent).For 19 out of 47 countries, the current nutrition data reflect the situation in 2000 or earlier. In two states, the most recent surveys pre-date the year 2000. The report raises an alarming approach on the critical gaps in nutrition data available across countries. Data gaps undermine the ability to target resources, develop policies and track progress. When you can't see it, you can't solve it. Thereto, without good data, we lag behind. Epidemiological studies have proved that people with very high BMI are predisposed to health risks with adiposity being a target for halting the prevalence of obesity $[12,18]$.

The quest for healthy diets is now a source for endless research and debates with focus on reducing the amounts of fats, sugar, and salt consumed. Obesity has now become a pressing health problem.Even though preliminary evidence from short-term studies prevails over trends in underweight and obesity, high quality controlled long-term data is lacking to document superiority. Nonetheless, underweight remains a significant public health concern in Central and East Africa and the Southern outskirts of Asia [19].

\section{Areas of Concern}

Dietary Changes; Enormous Shift to Fast Foods!

Large shifts have occurred in diets in the last 2 or 3 decades [20]. The present society seem to be appreciating a diet, rich in saturated fats, sugar and refined foods which are necessarily low in fiber [21]. Daily increased intake of caloric sweeteners may account for a larger share of both total energy and total carbohydrates consumed [22]. Fast foods are generally energy dense and nutrient poor and therefore increased intake might be interrelated to obesity [23,24]. Moreover, there has been a huge reduction in levels of physical activity. The implications of such diets are reflected in nutritional outcomes with changes in body composition, stature, morbidity and increased periods of disability adjusted life years (DALYs) [25].

The US provides a good case scenario of dietary changes in a developed country [26]. In his book, Eric Schlosser reports that Americans are now spending more money to purchase fast foods than in inputs such as higher education, computers and even new cars. In fact, American expenditure on fast food rose from around $\$ 6$ billion in 2001 to greater than $\$ 130$ billion in 201051. The daily caloric input of its population is shifting towards energy dense, nutrient poor foods and snacks [27]. Literature reveals that more meals are consumed way from home. The portion sizes served in the various eateries are vividly large $[28,29]$. The consumption of fruits and vegetables remain to be significantly low when compared to the recommended intakes [33].

\section{Obesogenic Environments}

An obesogenic environment is a collection of influences that the opportunities, surroundings or circumstances of life have on attenuating obesity prevalence on individuals or populations [12]. These obesogenic promoting conditions are believed to potentiate the growing obesity pandemic [31]. The good news is that public health experts are convinced that some of these environmental factors, namely the choice of means of transport and leisure-time activities, we can have control over. The two are key environmental features and individual domains that can be altered to modify engagement in physical activity [32]. A single factor does not just cause overweight and obesity. Evidence indicates that the environment has a significant effect on physical activity, diet, and obesity. Therefore concerning the current obesity epidemic, diet and physical activity cannot be examined in isolation [5]. To comprehend "why we eat what we eat" requires an understanding of the times, space, nature, culture and our surrounding social relationships. Food environment and the ability of the ecosystem to promote active living or physical activity can be closely related to health. Modern society solemnly could be described to support unhealthful eating patterns and physical inactivity [33]. Across the world, increasing urbanization is now recognized as a critical driver of obesity and related noncommunicable diseases prompting the need to understand how urban environments correlate with healthy living [34]. Features of neighbourhood environments such as access to unhealthy food, few opportunities to indulge in physical exercises may be related to the rise in obesity and associated disorders [12].Although research findings exist on the influence of the various neighbourhood features to obesity; conclusive evidence is still elusive and disparate. There are still gaps in knowledge.

Rapid Drift from Being Physically Active To Sedentary Lifestyles Physical inactivity has received the attention as one of the leading potentiating factors for global mortality contributing significantly to the burden of NCDs [35]. Evidence from available data alludes that about 31 per cent of the population in the world is not meeting the minimum recommendations for physical activity [36,37]. In 2009 the global prevalence of physical inactivity was 17 per cent [38]. The preceding year, 2010 the trends were increasing, WHO reported that around 23 per cent of adults aged 18 years and over were less active (women 27 per cent and men 20 per cent). At the same time, in 2010, 81 per cent of adolescents aged 11- 17 years were found to be physically inactive worldwide.

Individuals who are insufficiently active are said to have a 20-30 present increased risk fold of death when compared to a person who is sufficiently active [39]. Physical activities or exercise may cut down extra energy gained therefore establish caloric control Physical inactivity is a global challenge especially by the risks it conveys to the overall well-being $[40,41]$. In the meantime, Lee and colleagues presented convincing evidence that physical inactivity is associated with 6-10 per cent of deaths from non-communicable diseases 
worldwide [42]. The study farther revealed that the estimates are even higher for specific conditions such as 30 per cent for ischemic heart diseases. Increasing urbanization, being less active during leisure time, sedentary behaviour at places of work and homes and rapid rise in the economy has propagated a decrease in occupational, physical activity in both adults and children [43]. In the Philippine schools, the children are engaged in activities such as classroom washing and environment cleaning whereas in China the children are excluded from such activities to give room for more study time. This may explain the varying levels of engagement in physical activity [44]. Likewise, in the African region, rural-urban migration is correlated with reductions in physical activity [45]. This challenge will be more worse going by the estimates that by 2030 the world will be 60 per cent urban and 90 per cent of this growth will occur in low and middle-income countries in Africa and Asia, where the burden of malnutrition is brunt [46].

On the contrary, regular physical activity is said to decrease the risk of respiratory problems such as depression, diabetes, high blood pressure cancers of the colon and breast [47]. In another study that covered 34 countries, including China, US and Mexico, they observed steeper risk gradients of overweight with more television viewing periods in 22 countries representing 65 per cent of the observations [39]. The results were consistent with emerging evidence linking television viewing to a higher prevalence of obesity and overweight in adolescents in Australia, US and Netherlands [48]. The ways relating television viewing to overweight and obesity among the youth are more intakes of energy dense-foods during screen time or most likely from the influence of food adverts [49]. The reduced energy expenditure during screen time takes the place of physical activity. However, there is still limited data to vividly demonstrate verifiable patterns of physical activity especially among the youths [50-52].

\section{Conclusion}

This review has summarized the developing literature on the double burden of malnutrition with dominance on overweight, obesity and diet related non-communicable diseases. Malnutrition can be manifested as an imbalance, a deficiency or an excess in a person's intake of energy and or nutrients.Paradoxically, both forms exist in today's society. This work attests that as undernutrition is observed to be decreasing in some parts of the globe, the rate of decline is not at per with the population growth. Over nutrition on the other hand, is encroaching at higher speed than expected in the same countries. It is has also come to our notice that childhood and adolescent obesity is on the rise though adulthood obesity prevalence is still skyrocketing. Many countries are following this trajectory and the probability of the situation getting worse is on course if proper action is not taken. Despite the available data showing an increase in prevalence of overweight and obesity, yearly data gaps exists hence making it a hurdle to derive a consistent pattern. Finally, findings from this paper reinforce the urgency to map out, capitalize on data required and build on the capacity to expand on indicators driving this menace.

\section{References}

1. Global Nutrition Report (2017) Nourishing the SDGs. Bristol, UK: Development Initiatives.

2. Schmidhuber J, Shetty P (2005) The nutrition transition to 2030. Why developing countries are likely to bear the major burden. ActaAgriculturaeScand Section C 2: 150-166.

3. Weisz G, Olszynko-Gryn J (2009)The theory of epidemiologic transition: the origins of a citation classic. Journal of the History of Medicine and Allied Sciences 65: 287-326.

4. Popkin BM (2003)The nutrition transition in the developing world. Development policy review 21: 581-597.

5. Popkin BM, Gordon-Larsen P (2004)The nutrition transition: worldwide obesity dynamics and their determinants. International journal of obesity 3: S2-S9.

6. Popkin BM, Slining MM (2013)New dynamics in global obesity facing low and middle income countries. Obesity Reviews 14: 11-20.

7. Bryant J (1969) Health and the developing world. Health and the developing world p345.

8. Musaiger AO, Al-Hazzaa HM (2012) Prevalence and risk factors associated with nutrition-related noncommunicable diseases in the Eastern Mediterranean region. International journal of general medicine 5: 199.

9. Gearon E, Tanamas S, Loh V, Stevenson C, Peeters A (2016). Track 5: Populations and population health. Childhood, World Obesity 17: 91-151.

10. Black RE, Allen LH, Bhutta ZA, Caulfield LE, De Onis M, et al. (2008) Maternal and child undernutrition: global and regional exposures and health consequences. The lancet 371: 243-260.

11. Deckelbaum RJ, Williams CL (2001) Childhood obesity: the health issue. Obesity 4: 239S-243S.

12. Stegenga H, Haines A, Jones K, Wilding J (2014) Identification, assessment, and management of overweight and obesity: summary of updated NICE guidance. BMJ 349: g6608.

13. Finkelstein EA, Khavjou OA, Thompson H, Trogdon JG, Pan L, et al. (2012) Obesity and severe obesity forecasts through 2030. American journal of preventive medicine 42: 563-570.

14. Obesity-Preventing, WHO (1997) Managing the global epidemic. Report of a WHO Consultation on Obesity. Geneva: Who 7-17.

15. Abarca-Gómez L, Abdeen ZA, Hamid ZA, Abu-Rmeileh NM, Acosta-Cazares B, et al. (2017) Worldwide trends in body-mass index, underweight, overweight, and obesity from 1975 to 2016: a pooled analysis of 2416 population-based measurement studies in $128 \cdot 9$ million children, adolescents, and adults. The Lancet 390: 2627-2642.

16. NCD Risk Factor Collaboration (2016) Trends in adult bodymass index in 200 countries from 1975 to 2014: a pooled analysis of 1698 population-based measurement studies with 19• 2 million participants. The Lancet 387: 1377-1396.

17. World Health Organization (2017) Accelerating nutrition improvements in Sub-Saharan Africa: strengthening nutrition surveillance: final report 2012-2016. World Health Organization. https://apps.who.int/iris/handle/10665/255421. License: CC BY-NC-SA 3.0 IGO

18. Hales CM, Carroll MD, Fryar CD, Ogden CL (2017) Prevalence of obesity among adults and youth: United States, 2015-2016. National Center for Health Statistics. Data Brief 1-8.

19. Union A (2006) Status of food security and prospects for agricultural development in Africa. In Mali: AU Ministerial Conference of Ministers and Agriculture.

20. Troesch B, Biesalski HK, Bos R, Buskens E, Calder PC, et al. (2015) Increased intake of foods with high nutrient density can help to break the intergenerational cycle of malnutrition and obesity. Nutrients 7: 6016-6037.

21. Musaiger AO, Al-Hazzaa HM (2012) Prevalence and risk factors associated with nutrition-related noncommunicable diseases in the Eastern Mediterranean region. International 
journal of general medicine 5: 199 .

22. DiMeglio DP, Mattes RD (2000) Liquid versus solid carbohydrate: effects on food intake and body weight. International journal of obesity 24: 794.

23. Harrington S (2008)The role of sugar-sweetened beverage consumption in adolescent obesity: a review of the literature. The Journal of School Nursing 24: 3-12.

24. Malik VS, Schulze MB, Hu FB (2006) Intake of sugar-sweetened beverages and weight gain: a systematic review-. The American journal of clinical nutrition 84: 274-288.

25. Popkin BM (2011) Contemporary nutritional transition: determinants of diet and its impact on body composition. Proceedings of the Nutrition Society 70: 82-91.

26. French SA, Story M, Neumark-Sztainer D, Fulkerson JA, Hannan P (2001) Fast food restaurant use among adolescents: associations with nutrient intake, food choices and behavioral and psychosocial variables. International journal of obesity 25:1823.

27. Nielsen SJ, Siega Riz AM, Popkin BM (2002) Trends in energy intake in US between 1977 and 1996: similar shifts seen across age groups. Obesity 10: 370-378.

28. Jeffery RW, Utter J (2003)The changing environment and population obesity in the United States. Obesity 11: S12-S22.

29. Nielsen SJ, Popkin BM (2003) Patterns and trends in food portion sizes, 1977-1998. Jama 289: 450-453.

30. Haines P, Hama M, Guilkey DK, Popkin BM (2003) Weekend eating in the United States is linked with greater energy, fat and alcohol intake. Obes Res 11: 945-949.

31. Swinburn B, Egger G, Raza F (1999) Dissecting obesogenic environments: the development and application of a framework for identifying and prioritizing environmental interventions for obesity. Preventive medicine 29: 563-570.

32. French SA, Story M, Jeffery RW (2001) Environmental influences on eating and physical activity. Annual review of public health 22: 309-335.

33. Booth SL, Sallis JF, Ritenbaugh C, Hill JO, Birch LL, et al. (2001) Environmental and societal factors affect food choice and physical activity: rationale, influences, and leverage points. Nutrition reviews 59: S21-S36.

34. Dietz WH, Gortmaker SL (1985) Do we fatten our children at the television set? Obesity and television viewing in children and adolescents. Pediatrics 75: 807-812.

35. Swinburn B, Egger G (2002) Preventive strategies against weight gain and obesity. Obesity reviews 3: 289-301.

36. Popkin BM, Duffey K, Gordon-Larsen P (2005) Environmental influences on food choice, physical activity and energy balance. Physiology \&behavior 86: 603-613.

37. Hosseinpoor AR, Bergen N, Kunst A, Harper S, Guthold R, et al. (2012) Socioeconomic inequalities in risk factors for noncommunicable diseases in low-income and middle-income countries: results from the World Health Survey. BMC public health 12: 912.

38. Monda KL, Gordon-Larsen P, Stevens J, Popkin BM (2007) China's transition: the effect of rapid urbanization on adult occupational physical activity. Social science \& medicine 64 : 858-870.

39. Robinson TN (2001) Television viewing and childhood obesity. Pediatric Clinics 48: 1017-1025.

40. Garland T, Schutz H, Chappell MA, Keeney BK, Meek TH, et al. (2011)The biological control of voluntary exercise, spontaneous physical activity and daily energy expenditure in relation to obesity: human and rodent perspectives. Journal of Experimental Biology 214:206-29.

41. Blair SN, Jacobs Jr DR, Powell KE (1985) Relationships between exercise and physical activity and other health behaviours. Public health reports 100: 172.

42. Lee IM, Shiroma EJ, Lobelo F, Puska P, Blair SN, et al. (2012) Effect of physical inactivity on major non-communicable diseases worldwide: an analysis of burden of disease and life expectancy. The lancet 380: 219-229.

43. World Health organization (2017) Global Health RisksMortality and burden of disease attributable to selected major risks. Cancer.

44. Tudor Locke C, Ainsworth BE, Adair LS, Du S, Popkin BM, et al. (2004) Comparison of Physical Activity and Inactivity Patterns in Chinese and Filipino Youth. Child Care Health Dev 33: 59-66.

45. Assembly UG (2011) Political declaration of the high-level meeting of the general assembly on the prevention and control of non-communicable diseases. New York: United Nations.A/ $\mathrm{RES} / 66 / 2$.

46. Abubakari AR, Lauder W, Jones MC, Kirk A, Agyemang C, et al. (2009) Prevalence and time trends in diabetes and physical inactivity among adult West African populations: the epidemic has arrived. Public health 123: 602-614.

47. Hallal PC, Andersen LB, Bull FC, Guthold R, Haskell W, et al. (2012) Global physical activity levels: surveillance progress, pitfalls, and prospects. The lancet 380: 247-257.

48. Giskes K, van Lenthe F, AvendanoPabon M, Brug J (2011) A systematic review of environmental factors and obesogenic dietary intakes among adults: are we getting closer to understanding obesogenic environments?. Obesity reviews 12: e95-e106.

49. Un-Habitat. (2009) Planning sustainable cities: global report on human settlements. Routledge.

50. Ogden CL, Carroll MD, Fryar CD, Flegal KM (2015) Prevalence of obesity among adults and youth: United States, 2011-2014 (pp. 1-8). National Center for Health Statistics Data Brief p1-8.

51. Haby MM, Markwick A, Peeters A, Shaw J,Vos, T (2011) Future predictions of body mass index and overweight prevalence in Australia, 2005-2025. Health promotion international 27: 250-260.

52. Schlosser E (2012) Fast food nation: The dark side of the allAmerican meal. Houghton Mifflin Harcourt.

Copyright: (C2019 Kutwah Moses Amram. This is an open-access article distributed under the terms of the Creative Commons Attribution License, which permits unrestricted use, distribution, and reproduction in any medium, provided the original author and source are credited. 